\title{
Etnicidade e memória entre quilombolas em Irará, Bahia*
}

\author{
Jucélia Bispo dos Santos ${ }^{1}$ \\ Faculdade Nobre de Feira de Santana
}

\section{Resumo}

Este trabalho faz uma apreciação do percurso histórico dos quilombolas da comunidade de Olaria, no município de Irará, no estado da Bahia. Esta região fica localizada a $6 \mathrm{~km}$ do distrito sede, foi fundada no final do século XIX por famílias de ex-escravos que resistiram à escravidão. A origem da ocupação inicial data de mais de cem anos, segundo a memória dos moradores mais antigos, as referidas terras, nas quais os atuais moradores residem, foram ocupadas num período anterior à Lei Áurea, assinada em 13 de maio de 1888 pela princesa Isabel do Brasil. A recordação dos nativos mais velhos abaliza que os primeiros moradores desse lugar chagaram à região por volta de 1840. Assim sendo, apresenta-se uma análise que identifica as dinâmicas interétnicas que foram constituídas em torno da memória dos quilombolas, nos períodos que vão da origem do município, na segunda metade do século XVII, aos dias atuais, quando essas comunidades foram conhecidas como remanescentes de quilombos.

Palavras-chave: Memória; etnicidade; quilombo; parentesco; resistência.

\begin{abstract}
This paper aims at analyzing the historical trajectory of the quilombolas community of Olaria county, in Irará town. This region is $6 \mathrm{~km}$ distant from Olaria county. It was founded late in the nineteenth century by descendant families of slaves who resisted to the slavery system. The origin of the initial settlement is more than a hundred years old, according to the memory of the old residents, the referred lands, in which the current residents live, were settled before Aurea Law had passed, signed in 13 of May of 1888 for the princess Isabel of Brazil.

Ethnicity and memory among quilombolas at Irará, Bahia

${ }^{1}$ Endereço para correspondências: Faculdade Nobre de Feira de Santana, Av. Maria Quiteria, 2116, Kalilândia, Feira de Santana, BA, 44025-250 (prof.jucelia@bol.com.br).
\end{abstract}




\section{HUMANAS}

According to the elderly, the first settlers arrived there around 1840. This study shows an analysis which identifies the inter-ethinic dynamics which have been constituted about the memory of quilombola people which is dated from the very beginning of the process of foundation of the county, in the middle of seventeenth century, to the present times, when these communities are known as remaining of quilombolas.

Keywords: Memory; ethicinity; quilombo; kinship; resistence.

\section{1 - Introdução}

locus desta pesquisa é a comunidade da Olaria a qual, portanto, faz parte do município de Irará-Bahia. O nome desse município tem origem tupi e designa uma espécie de formiga de asas brancas semelhante aos cupins: é uma alteração da palavra "arará", que por sua vez significa nascida na luz do dia, pois estas formigas surgem ao alvorecer do dia $^{2}$. No entanto, antes de passar a ser chamada de Irará a localidade era conhecida como Purificação dos Campos. Essa denominação persistiu até o final do século XIX, quando foi criado o município, a 08 de agosto de 1895.

A colonização de Irará começou na segunda metade do século XVII, com as entradas de Antônio Guedes Brito, mestre de Casa da Ponte. A Casa da Ponte abrangia desde o Rio de Contas até os limites de Sergipe, incluindo a Cachoeira de Paulo Afonso ${ }^{3}$. Anteriormente à entrada desse sertanista, temos a vinda dos jesuítas para essa região, os quais chegaram com a missão de catequizar os indígenas. Dessa iniciativa surgiu o aldeamento da Purificação que, nos dias atuais, pode ser visualizado por meio dos sítios arqueológicos que estão presentes nas seguintes regiões: comunidade de Brotas, vila de Caroba, Bento Simões e o distrito sede, a cidade de Irará.

O Conde da Ponte, João de Saldanha da Gama Mello Torres Guedes de Brito e a Condessa da Ponte D. Maria Constança de Saldanha Oliveira e Souza, desmembraram, no dia 21 de fevereiro de 1807, a sua gigantesca propriedade. João Peixoto Veigas, um português que veio para a Bahia por volta de 1640, filho de Fernão Peixoto de Viana e de Barbara Fernandes, passou a comandar parte das terras da Casa da Ponte.

\footnotetext{
${ }^{2}$ NOGUEIRA, A. Histórico do Municipio de Irará. Prefeitura Municipal de Irará, 1988.

${ }^{3}$ NEVES, E. F. Da sesmaria ao minifúndio (um estudo de história regional e local). Salvador: Editora da Universidade Federal da Bahia; Feira de Santana: Universidade Estadual de Feira de Santana, 1998.
} 
Em 1652 estas terras abrangiam as regiões do Paraguaçu, Itapororocas e Água Fria, incluindo também o atual município de Irará, então pertencente à região de Vila de São João Batista de Água Fria ${ }^{4}$, criada por força de Resolução Régia de 28 de abril 1727.

A colonização só se consolidou, de fato, nos solos do atual município de Irará a partir do avanço da pecuária no século XVIII, quando ocorreu a instalação de currais de gado em todo o sertão baiano, tais como o do capitão-mor, Antônio Homem de Afonseca e o de Diogo Alves Campos. Nesse período, os colonizadores ensejaram choques com as tribos dos Paiaiás, mas eles ofereceram resistência.

No decorrer dos anos, a região de Irará foi conquistando espaço político no projeto da colonização. Como exemplo desse sucesso ocorreu a criação da Vila da Purificação em 1842, com a mudança da vila de São João Batista da Água Fria (atual Água Fria). Com a implantação da vila ocorreu a ereção do Pelourinho, na atual Praça Pedro Nogueira, o qual era um poste de madeira com argolas de ferro em que os condenados pela justiça eram amarrados e chicoteados. Assim era exercida a justiça: através da aplicação das penas de açoite ou mutilação ${ }^{5}$. Naquele espaço, também eram afixados os editais, anúncios e outras ordens municipais de interesse público. A presença do pelourinho representou a efetivação e o reconhecimento da posse das terras, isto é, simbolizou o poder constituído.

A vila foi elevada à condição de cidade através lei estadual de 08.08.1895 com a denominação de Irará. Nesse período, o município era governado por intendentes, cujo primeiro fora Pedro Nogueira Portela. Posteriomente, surgiu a administração dos interventores: Elpídio Nogueira foi o primeiro a assumir o cargo em Irará. Somente em 1948 a cidade passou a ser a adminstrada por prefeitos, tendo Elísio dos Reis Santana como o primeiro representante. ${ }^{6}$

Atualmente, Irará possui 25.531 habitantes e uma área total de 271,7 $\mathrm{km}^{2}$, distando sua sede cerca de $137 \mathrm{~km}$ de Salvador, capital do Estado. Este município possui as seguintes rodovias: a BA-084, via Coração de Maria (de ligação à capital do estado); a BA-504 via Santanópolis ( que liga à cidade de Feira de Santana).

${ }^{4}$ Idem.

${ }^{5}$ ARAGÃO, A. Pelourinhos da Madeira, Funchal, 1959, Luís Chaves, Os Pelourinhos de Portugal, Gaia, 1930

${ }^{6}$ NOGUEIRA, A. Histórico do municipio de Irará. Prefeitura Municipal de Irará, 1988. 


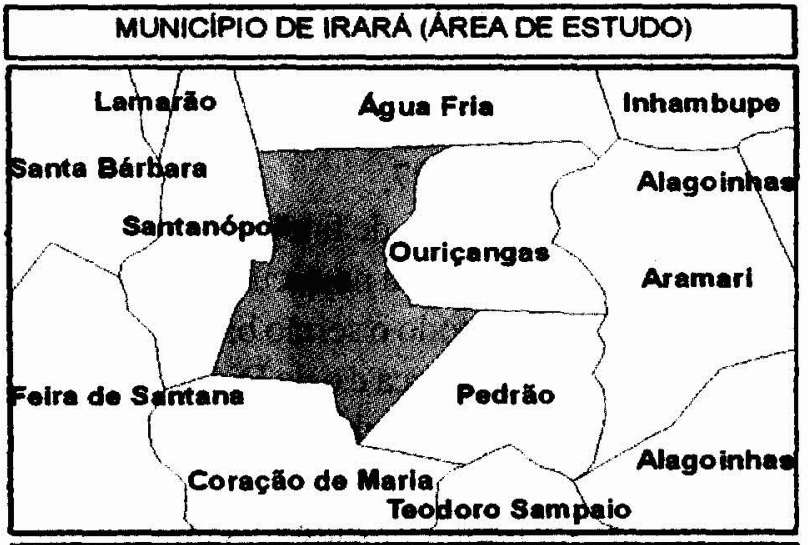

MUNICIPIO DE IRARA NAREGIAO ECONOMICA DO PARAGUACU

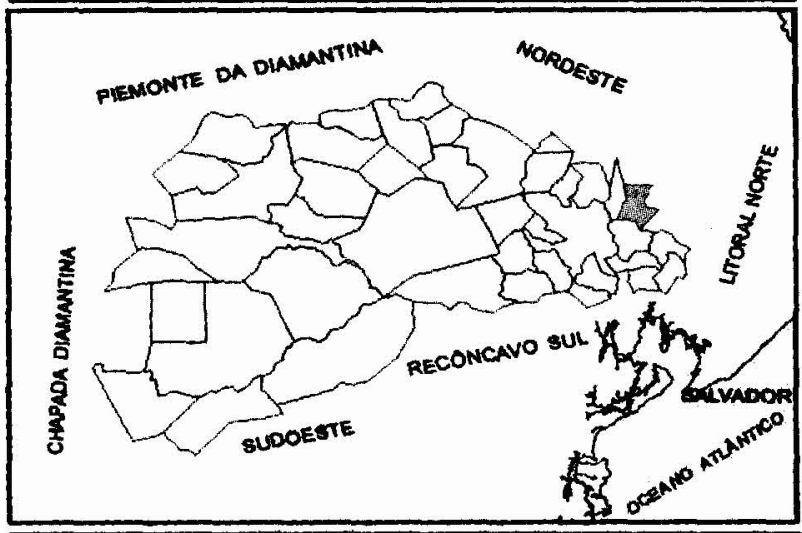

LOCALIZACCAO DA AREA DE ESTUDO NO ESTADO DA BAHIA

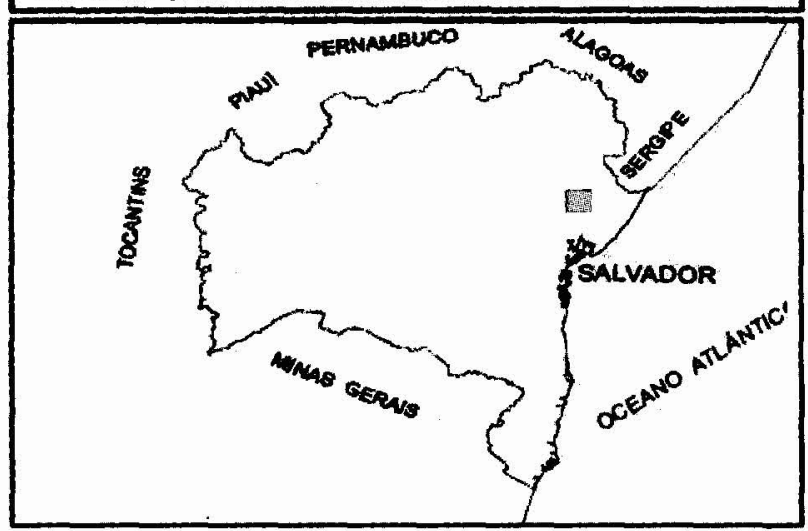

Figura 1

Divisão territorial da Bahia, região do Paraguaçu e do município de Irará Fonte: IBGE, 2000. 
Sua zona político-administrativa é a do Paraguaçu, que é composta de 42 municípios que, em sua maior parte, localizam-se no semi-árido baiano. Essa região tem uma área de $34.129 \mathrm{~km}^{2}$, ocupando, portanto, $6,05 \%$ do território Estado da $\mathrm{Bahia}^{7}$. De acordo com a regionalização do IBGE, Irará pertence à microrregião de Feira de Santana e à mesoregião centro nortebaiano, a qual é considerada uma das regiões mais povoada do território do estado: sua densidade demográfica em 2000 , de $36,63 \mathrm{hab} . / \mathrm{km}^{2}$. Esse espaço limita-se ao recôncavo baiano e ao do agreste de Alagoinhas.

A lei estadual de n. 614, de 18 de agosto de 1905 esclerece os limites do município de Irará: ${ }^{8}$

\begin{abstract}
O município de continuará a ter os seus limites antigos, excluída dele a parte que constituiu a frequezia do Santissímo Coração de Maria, em virtude da lei n. 489 de 6 de junho de 1853 , e que mais tarde constituiu-se, pelo acto de 28 de março de 1891 , vila sob a mesma denominação do Santíssimo Coração de Maria, com seus limites declarado e conhecidos.
\end{abstract}

Os atuais limites do território de Irará são assim configurados: ao norte, Água Fria; ao sul, Coração de Maria; ao leste, Ouriçangas; ao oeste, Santanópolis; ao sudeste, Pedrão. Apresenta-se nesse município uma rede hidrográfica modesta, sem rios perenes, sendo divisor de águas de dois importantes rios: o rio Seco e o rio Parmirim?.

Irará está centrado numa zona de transição, entre o recôncavo e os tabuleiros semi-áridos do Nordeste. Essa região apresenta um clima seco, solos rasos e pedregosos. Sua vegetação é constituída de espécies que se misturam: floresta tropical, na região leste e caatinga (cactos, pequenas árvores e arbustos), na região oeste.

Na vegetação da caatinga predominam: aroeira, angico, baraúna, cardeiro, coroa de frade, catingueira, craibeira, sucupira, jurema branca e jurema preta, juazeiro, jucá, macambira, marmeleiro, oiticica, pau d'arco, pereiro,

7 IBGE. Enciclopédia dos municípios brasileiros. Rio de Janeiro, IBGE, 1957.

8 IBGE. Bahia, limites municipais regulados por ordens régias, leis municipais e estaduais. Enciclopédia dos municipios brasileiros. Rio de Janeiro, IBGE, 1957.

${ }^{9}$ Idem. 


\section{HUMANAS}

quixabeira, velame, xiquexique. Tal vegetação apresenta um aspecto de plantas sub-xerófilas, decíduas, cujos componentes predominantes são pequenas árvores ou arbustos, geralmente espinhosos, formando grupamentos ora densos, ora com árvores esparsas.

Na parte leste, encontra-se uma maior diversidade de espécies vegetais: palmeiras, como o dendê e o babaçu, além de outras árvores, como: tambor, turco, mulungu, braúna, umbaúba, umburana de cambão, sucupira, etc. Esta parte de Irará é ainda ocupada por pastagens e plantações agrícolas, como a produção de fumo.

Segundo os dados do IBGE, o município de Irará está situado no polígono das secas ${ }^{10}$. A temperatura média oscila entre $22^{\circ} \mathrm{e} 24^{\circ}$, com as médias máximas ficando em torno de $30^{\circ} \mathrm{e}$ as médias mínimas por volta de $19^{\circ}$. A precipitação média situa-se em torno de $844,0 \mathrm{~mm}$ anuais. Quando aumenta a umidade relativa do ar, há ocorrências de neblina, sobretudo no período do inverno, entre junho e agosto, como ápice. ${ }^{11}$

Embora, os dados oficiais atribuem à região o perfil do semi-árido, poucos moradores de Irará, reconhecem que a localidade possui essas características climáticas. Pois, para essas pessoas, o codinome "sertão" está vinculado à seca, à incapacidade produtiva da economia, ao subdesenvolvimento cultural: enfim tem a ver com atraso. Essas considerações estão presentes nos depoimentos de populares, tais como: "Irará não é sertão, pois está um pouco perto do litoral... E não é recôncavo também, mas aqui tem massapê que só dá perto do recôncavo" ${ }^{12}$. A região é também identificada como uma área de transição, uma espécie de "porta para o Sertão".

A seca é vista como uma eterna ameaça nessa região. Durante o verão, especialmente no mês de dezembro o clima torna-se mais seco e a temperatura do solo chega a $40^{\circ} \mathrm{C}$. O sol forte acelera a evaporação da água de lagoas e córregos que, nos trechos mais estreitos, secam e param de correr.

\footnotetext{
${ }^{10} \mathrm{O}$ Polígono das Secas é um território reconhecido pela legislação como sujeito a períodos críticos de prolongadas estiagens. Compreende os estados do Piauí, Ceará, Rio Grande do Norte, Paraíba, Pernambuco, Alagoas, Sergipe, Bahia e Norte de Minas Gerais. Trata-se de uma divisão regional efetuada em termos político-administrativo e não corresponde à zona semi-árida, pois apresenta diferentes zonas geográficas com distintos índices de aridez, indo desde áreas com características estritamente de seca, com paisagem típica de semi-deserto a áreas com balanço hídrico positivo. MINTER , Plano Integrado para o Combate Preventivo aos Efeitos das Secas no Nordeste. Série Desenvolvimento Regional. $N^{\circ} 1$. Brasília. 1973

"IBGE. Enciclopédia dos municípios brasileiros. Rio de Janeiro, IBGE, 1957.

12 TRANSCRIÇÃO DO DEPOIMENTO DO SR. SÓSTENES PAES COELHO. Em colaboração para o projeto de história oral de Irará-12/07/1985.
} 
Nos períodos de estiagem ocorrem movimentos migratórios caracterizados pela saída das pessoas da região. Esse fator contribui com a apresentação de um quadro econômico empobrecido, devido especialmente ao castigo da irregularidade das chuvas.

Irará é dividido em zona rural e zona urbana. Além do distrito-sede de Irará, o município também é composto pelas vilas de Bento Simões e da Caroba, e por povoados e fazendas que formam sua zona rural.

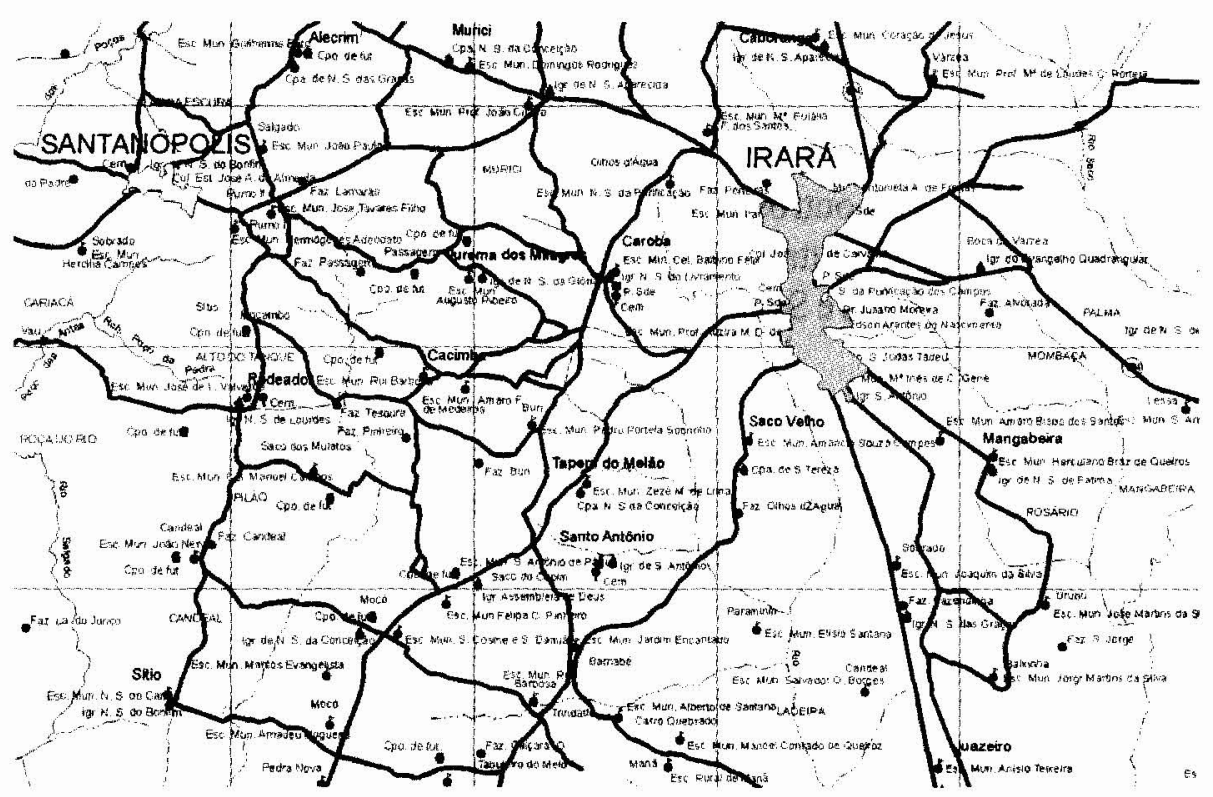

Figura 2

Mapa de Irará: zona urbana e zona rural.

Na sede municipal existem duas agências bancárias, uma federal e uma privada, além de possuir uma agência de Correio e Telégrafos. Para o atendimento da população, existe um hospital conveniado ao SUS, dispondo de vinte leitos. $\mathrm{O}$ abastecimento de água é feito pela Embasa, e 26,5\% domicílios possuem acesso à água encanada ${ }^{13}$.

Na cidade, o comércio é bastante diversificado, sendo encontrados: supermercados, lojas de calçados e roupas, postos de gasolina, salões de beleza, bares, entre outros. Já o setor industrial não é tão expressivo no município:

${ }_{13}$ IBGE. Enciclopédia dos municipios brasileiros. Rio de Janeiro, IBGE, 1957. 
Irará possui apenas pequenas indústrias de farinha, algumas madeireiras, as de confecçães e prestação de serviços em facção, e granjas com abatedouro. ${ }^{14}$

Aos sábados é realizada a feira livre de Irará, uma das mais importantes da micro-região de Feira de Santana. Nesses dias, o ritmo da cidade muda: as ruas são tomadas por uma multidão bem heterogênea que aumenta os fluxos e mobilidades sócio-econômicas. Na Praça da Purificação são erguidas barracas de madeira que formam as bancas de hortifrutigranjeiros, roupas, utilidades domésticas e artesanatos, como: objetos de cerâmica, esteiras, cestos, chapéus de palha, chicotes, móveis, artefatos de couro para montaria, dentre outros. No mercado municipal são vendidos carnes, carnede-sol, requeijão, beiju, farinha, feijão, milho, fumo de corda, cachaça, manteiga-da-terra, dentre outros elementos, que atendem ao abastecimento da população local e de outras cidades próximas, como Coração de Maria, Água Fria, Ouriçangas e Santanópolis. A feira se dá durante as madrugadas e manhãs de sábado.

O campo é formado por minifúndios e fazendas. Na zona rural destacam-se as propriedades de pequeno porte, onde se desenvolve a agricultura de subsistência. Destacam-se também, a avicultura, a apicultura e a pecuária, com a criação de bovinos para o abate no mercado local. A agricultura é produzida em pequenas e médias propriedades com utilização de mão-deobra familiar ${ }^{15}$, técnicas tradicionais e rudimentares e se destina a subsistência da família. A mão-de-obra doméstica aplicada na agricultura se organiza em torno da e para a família, por uma lógica que reúne saberes e valores que asseguram a reprodução da unidade familiar.

Os ciclos da produção agrícola são anuais e semi-anuais, ou seja, de estação em estação, o que promove uma dificil subsistência das populações rurais de Irará, uma vez que essas pessoas dependem dos efeitos climáticos, como a chuva, para obterem boas safras. Deste modo, grande parte da subsistência econômica dos individuos que moram nesse município está intimamente ligada ao sustento básico, que é promovido através das escassas produções que advêm de uma produção tradicional.

\footnotetext{
14. NOGUEIRA, Aristeu. Histórico do município de Irará. Prefeitura municipal de Irará, 1988.

${ }^{15}$ Para Abramovay a agricultura familiar não emprega trabalhadores permanentes, podendo, porém, contar com até cinco empregados temporários. Agricultura patronal pode contar com empregados permanentes e/ou temporários. ABRAMOVAY, R., Agricultura, diferenciação social e desempenho econômico. Projeto IPEA-NEAD/MDA - Banco Mundial, São Paulo, FEA-USP, 2000, p. 03.
} 
Os principais produtos agrícolas produzidos em Irará são: mandioca, milho, feijão e fumo. Vale salientar que Irará já foi um grande produtor de fumo, especialmente, no século XIX e quase todo o século $\mathrm{XX}^{16}$. Hoje, no entanto, a produção está dratiscamente reduzida, em relação ao volume ocorrido no passado. Segundo informações da EMBRAPA ${ }^{17}$ local, o declínio da cultura do fumo foi provocado não somente pelos problemas decorrentes da seca, mas também pela concorrência do mercado externo que oferece o produto por um valor bem abaixo do praticado no mercado local. A queda da produção e da venda do fumo se deu por conta também dos entraves nos créditos agrícolas, cujos custos são muito altos. $\mathrm{O}$ centro urbano guarda e memória da fase da prosperidade da economia fumageira, através de grandes trapiches, prédios que têm uma arquitetura glamurosa que lembra uma fase de opulência. Nos finais dos anos oitenta do último século, a produção de fumo iraraense passou por uma crise especialmente por conta da seca. Nos dias atuais, ainda mantem-se a produção fumageira, embora, reduzida.

Hoje em dia, a mandioca é o principal sustento do município. Quase toda a produção de mandioca de Irará é utilizada para a fabricação de farinha, que é vendida nas cidades circunvizinhas e no mercado municipal local. A farinha é vista em Irará, como o principal termômetro que mede a economia local: quando falta a farinha (geralmente por conta da seca), falta tudo também. Ou seja, a economia de Irará gira em torno da produção e da venda de farinha.

Além da produção agrícola, os moradores do campo também contam com a criação de porcos, galinhas e ovelhas. As atividades ligadas à pecuária são executadas, mas pelo uso exclusivo dos grandes proprietários de terras, isto é, por homens que são considerados fazendeiro ${ }^{18}$, mas que em sua a maioria não residem na zona rural. Esses criadores possuem geralmente atividades ligadas à criação de rebanhos bovinos e muares, sendo que também já existem fazendas de criação de avestruz.

\section{2 - As comunidades de quilombos de Irará}

A Fundação Palmares aponta que existem vários núcleos de resistência negra, no Brasil, conhecidos como comunidades remanescentes de quilombos.

\footnotetext{
${ }^{16}$ Idem.

${ }^{17}$ Empresa Brasileira de Pesquisa Agropecuária.

${ }^{18}$ Idem.
} 
Essa demarcação procedeu de uma catalogação feita, nas diversas regiões do país ${ }^{19}$. Conforme elementos recolhidos por meio de pesquisas, esses grupos são distinguidos através da relação de descendência de negros dos quilombos.

De acordo com a primeira configuração espacial dos territórios das comunidades remanescentes de antigos quilombos no Brasil, atualmente, existem no Brasil cerca de 2 milhões de quilombolas ${ }^{20}$. Nos dias atuais, a Bahia possui 396 grupos registrados como comunidades de quilombos. Esses estão espalhados entre os 417 do estado. Conforme a abordagem de Sanzio a extensão territorial dos quilombos e as revoltas dos povos negros no Brasil, à configuração territorial etnológica africana no país e a distribuição da população negra em várias regiões da Bahia favoreceram o mapeamento dos remanescentes de quilombos no país que mostra os territórios quilombolas que já foram demarcados desde a Constituição de 1988, inclusive na micro-região de Feira de Santana, onde o município de Irará está inserido, que tem as seguintes comunidades:

\section{Tabela 1}

Configuração espacial das comunidades de quilombos da Micro-região de Feira de Santana.

\begin{tabular}{ccc}
\hline $\begin{array}{c}\text { Configuração espacial - Centro de Cartografia Aplicada e Informação } \\
\text { Geográfica da UNB }\end{array}$ \\
\hline Feira de Santana & 4 & Lagoa do Negro \\
& Lagoa Grande \\
& Matinha \\
& & Roçado \\
Água Fria & 1 & Paramirim dos Crioulos \\
Irará & 4 & Crioulo \\
& & Mocambinho \\
& & Olaria \\
Ter- Nova & 2 & Tapera \\
& & Caboatã \\
& & Malemba \\
\hline
\end{tabular}

${ }^{19}$ ANJOS, R. S. A. Projeto mapeamento dos remanescentes de quilombos no Brasil - sistematização dos dados e mapeamento - Relatório Técnico, Fundação Palmares, Brasília, 1997.

${ }^{20}$ Fundação Cultural Palmares (FCP), do Ministério da Cultura. Projeto de melhoria da identificação e regularização de terras das comunidades quilombolas brasileiras, 2003. 


\section{Etnicidade e memória entre quilombolas em Irará, Bahia}

Jucélia Bispo dos Santos

Esta coleta foi feita pelo Centro de Cartografia Aplicada e Informação Geográfica do Departamento de Geografia da Universidade de Brasília(UnB). Conforme as informações do CIGA, existem em Irará quatro comunidades de quilombos ${ }^{21}$ : Crioulo, Olaria, Mocambinho e Tapera. Vale salientar que, Crioulo, Olaria e Tapera fazem parte do próprio município de Irará; Tapera está localizada a sete quilômetros de distância do distrito-sede, ao sudeste de Irará. Olaria fica centrada na região da Serra de Irará, ao noroeste. Já Mocambinho, atualmente, faz parte do município de Santanópolis.

A Fundação Palmares executou uma demarcação dessa região tomando como ponto de referência os dados do IBGE $^{22}$, pois, para as pesquisas oficiais, essas regiões são divididas através de limites geográficos que se estabelecem no espaço por meio de vales, rios, montanhas, estradas, ou seja, através de limites visíveis.

Ao noroeste do município de Irará, distante a cinco quilômetros do distrito-sede, entre as terras cortadas pelas serras do Urubu e do Periquito, encontra-se a comunidade da Olaria, em torno desta rodovia que liga o município de Irará aos municípios de Santanópolis e Feira de Santana. Vale ressaltar que para se chegar até este lugar, percorre-se a BA 504, a única estrada que permite o acesso à região.

À região remanescente de quilombo da Olaria que foi fundada no século XIX por ex-escravos que saíam do cativeiro e passaram a ocupar as terras da Serra de Irará. No decorrer do percurso histórico, a comunidade foi recebendo denominações novas. Estas são novas nomenclaturas que são utilizadas para designar a região que foi fundada, antes da lei Aura, as quais correspondem às seguintes comunidades: Olaria, Mangueira, Periquito e Urubu. Vale a pena salientar que, os nomes dessas comunidades estão relacionados com uma tradição local que demarcam as seguintes características:

\footnotetext{
${ }^{21}$ Idem.

${ }^{22}$ Fundação Cultural Palmares (FCP), do Ministério da Cultura. Projeto de melhoria da identificação e regularização de terras das comunidades quilombolas brasileiras, 2003.
} 


\section{HÜMANAs}

\section{Quadro 1 \\ Origem do significado dos nomes das comunidades de pretos da Serra de Irará.}

\begin{tabular}{|l|l|}
\hline \multicolumn{2}{|c|}{ O significado dos nomes: } \\
\hline OLARIA & $\begin{array}{l}\text { Os primeiros moradores desenvolviam os serviços do } \\
\text { oleiro. Os homens faziam telhas e as mulheres faziam } \\
\text { objetos utilitários: potes, panelas, caborés, engana-gato } \\
\text { (segundo os nativos esta designação serve para denominar } \\
\text { uma espécie de panea de barro sem tampa que atraiam os } \\
\text { gatos para a execução do roubo carnes, no processo de } \\
\text { cozimento dos alimentos), etc. }\end{array}$ \\
\hline PERIQUTTO & $\begin{array}{l}\text { Segundo os moradores dessa commidade, esse local } \\
\text { sempre foi refígio de muitos periquitos, ouro e petróleo, } \\
\text { uma espécie de Eldorado. As pessoas mais velhas contam } \\
\text { que circulava um carneiro de ouro no topo da serra, o que } \\
\text { significava que ali era um lugar de riquezas minerais. }\end{array}$ \\
\hline MANGUEIRA & $\begin{array}{l}\text { Nesse lugar existiam muitas mangueiras, por isso a } \\
\text { comunidade recebeu essa nomenclatura. }\end{array}$ \\
\hline URUBU & $\begin{array}{l}\text { Esse lugar é habitat natural dos urubus da regão. Segundo } \\
\text { os moradores, esses animais dormem nesse espaço da } \\
\text { Serra. "Logo que o dia amanhece, eles vão passear em } \\
\text { outros lugares do munićpio, mas ao entardecer eles vêem } \\
\text { dormir no topo da serra." }\end{array}$ \\
\hline
\end{tabular}

De acordo com a memória dos nativos das comunidades remanescentes de quilombos, essa região é dividida a partir da seleção de características que se manifestam nos traços de sua identidade que tem a ver com o passado vinculado ao cativeiro. Dessa forma, as pessoas se diferenciam das outras que estão ao seu redor, sabendo quais são as que fazem parte do grupo e quais não fazem parte. Essas categorias "de dentro" $\mathrm{e}$ "de fora" apontam para o limite étnico que definem os grupos ${ }^{23}$. Os traços étnicos raciais fundamentam a atração e a separação dos mesmos. Alguns critérios são acionados pelos nativos na afirmação da identidade do grupo como: sobrenome, memória do cativeiro, fenótipos raciais, locais de moradia, parentesco e situação econômica.

\footnotetext{
${ }^{23}$ POUTIGNAT, P. e STREIFF-FENART, J. Teorias da etnicidade, seguido de grupos étnicos e suas fronteiras de Fredrik Barth. São Paulo, Unesp, 1998.
} 


\section{Etnicidade e memória entre quilombolas em Irará, Bahia Jucélia Bispo dos Santos}

Portanto, a etnicidade apresenta-se como um importante elemento diacrítico, sendo indispensável como identidade social. Esses elementos estão presentes nas relações sociais que os descendentes dos ex-escravos contruíram após a Abolição na relação deles com os outros que estão ao seu redor. Estes outros fazem parte das chamadas comunidades de brancos, que são as seguintes: Açougue Velho e Murici. Estas comunidades abrigam as famílias que possuem os seguintes sobrenomes: Pinto, Mascarenhas, Lopes, Pinheiro e Carneiro. Arepresentação étnica racial destes espaços, especialmente a do Murici é composta de pessoas brancas, que se casam entre si.

As pessoas que residem na comunidade da Olaria lidam com um processo de reconstrução identitária típica das comunidades quilombolas, pois existe uma afirmação delas, enquanto grupos que promovem um diferencial dos "outros", o que implica a construção de discursos de auto-afirmação étnica, que se baseiam no passado vinculado à escravidão. Nos depoimentos, as pessoas se identificam como negros e descendentes de escravos. Assim, rememoram com nitidez pai e mãe, avô e avó, bem como traçam com facilidade suas genealogias até o cativeiro. Produzem, assim, uma representação sobre a escravidão destacando o papel central da família escrava.

Os moradores mais velhos da Olaria, como o senhor João dos Santos, conhecido na comunidade com Seu Dil, explicam que a formação dessa região está pautada com a relação que as pessoas estabeleceram nesse espaço e a história de vida que elas têm e que são incluídas com a memória cativeiro ${ }^{24}$ :

Eu não arcansei o cativeiro, mas o povo mais velho conta sobre o cativeiro. Aqui nessa região tem muita gente que tem rama com o cativeiro... A Olaria toda! Essa região toda que senhora tá veno, fazia parte da Olaria. Era uma só propriedade. Hoje o povo não gosta de falar que é da Olaria, como vergonha... Mas, toda essa região que vosmicê está veno fazia parte da Olaria. Pega essa região toda da Serra do Urubu, Serra do Piriquito e da Mangueira. Começava lá de onde é o Açogue Veio.

${ }^{24}$ ENTREVISTA: Senhor João de Jesus, morador da localidade de Olaria, cedida no dia 14/08/2005. 


\section{HUMANAs}

\begin{abstract}
Depois o foi mudano de nome. Hoje o povo não quer ser da Olaria porque tem vergonha de ser nego... O povo diz que ser da Olaria é ser nego... Lá o Murici sempre foi terra de branco... Hoje o povo já chama isso aqui de Murici II... Mas, tudo é história porque aqui tudo é Olaria na verdade...
\end{abstract}

Neste discurso, é possivel observar a memória do cativeiro, fortemente marcada por algumas identidades sociais historicamente construídas. As pessoas se reconhecem e são distinguidas conforme as características étnicas que se respaldam nas relações de parentesco com a escravidão. Ao mesmo tempo que existe a memória da cativeiro, essa memória coletiva também é negada através da interação entre os membros. Assim, ocorrem os movimentos de mobilização e desmobilização, por conta dos preconceitos gerados pelos estigmas existentes no interior do grupo e sofridos por ele. Tendo em vista o modo como a sociedade concebe indivíduos estigmatizados, 0 encontro entre estes grupos e o meio social abrangente, coloca-se em evidência o efeito do estigma, fator que provoca uma situação angustiante para todos os envolvidos ${ }^{25}$. Esta rejeição também pode designar uma fuga, na medida que o grupo pode ser utilizado como amparo ou escudo contra uma discriminação já prevista. Nesse caso, o estigmatizado, ao entrar numa situação social mista, pode passar a responder de maneira defensiva, tentando aproximar-se com retraimento ou através de uma atitude hostil, incômoda aos outros, temendo a rejeição.

As pessoas da comunidade da Olaria afirmam que experimentam conflitos étnico-raciais com os outros que estão ao seu redor. Eles não se misturam. É comum surgirem conflitos diretos em situações de festas populares e até mesmo quando as crianças se encontram na escola. No local existe uma distinção que separa os descendentes dos ex-escravos, das outras pessoas. Por conta dessa questão, em algumas situações, muitos sujeitos que residem no território remanescente de quilombo negam sua identidade, posto que ser da Olaria, por exemplo, sempre representou exclusão da socieade regional, já os ancestrais da Olaria têm um passado vínculado à escravidão.

${ }^{25}$ GOFFMAN, E. (1988). Estigma: notas sobre a manipulação da identidade deteriorada. (M. B. M. L. Nunes, Trad.). Rio de Janeiro, Zahar Editores. (Original publicado em 1963). 
Nessa região, o negro é visto como "diferente" devido a sua cor. Essa "diferença" aumenta ainda mais o índice de rejeição e discriminação por parte de muitos brancos, que ainda vêem os negros como "seres inferiores"26. A negação da identidade negra por alguns moradores da Olaria advém da ação do racismo no cotidiano daquelas pessoas, sendo, muitas vezes, manifestado por determinados sujeitos que residem ao seu redor. Vale ressaltar que a estruturação desses grupos não é um fenômeno isolado, uma vez que esses processos estão relacionados com características políticas, econômicas e culturais que foram estatabelecidas conforme o projeto da estruturação social que se organizou no projeto da colonização em várias partes do mundo. No contexto descrito, ocorre o acirramento das "identidades étnicas", considerando-se que a etnicidade é resultante da relação com o outro étnico, sendo posta em pauta pelos sujeitos em virtude de necessidades impostas ${ }^{27}$. A etnicidade, portanto, aparece nas relações sociais como uma dinâmica que assume características determinadas em função dos conflitos étnicos impostos pelo entorno regional.

Percebe-se que a comunidade investigada, apesar de ter demonstrado a existência de conflitos em relação à própria identidade, manifestou, ainda que inconscientemente, algumas situações que evidenciaram a existência de processos que contribuem para a constituição de sua identidade negra. Nessas relações aparecem as marcar da etnicidade: a criação de limites e critérios de auto-adiscrição subjetivos, e a de um discurso social determinado de diferenciação cultural, pois eles são eleitos conforme a criação dos termos de inclusão e de exclusão ${ }^{28}$.

No discurso de Sr. João, a etnicidade aparece como uma unidade discreta, dotada de uma cultura, de história e de comportamentos específicos que os separam eles dos diferentes sujeitos que residem ao redor, como os que não têm ancestrais escravos. De acordo sua fala, é possível perceber elementos que anunciam como ocorre esse processo de diferenciação dos sujeitos que residem na comunidade, tanto interna quanto externa. De acordo com Weber essa questão pode expressa da seguinte forma ${ }^{29}$ :

\footnotetext{
${ }^{26}$ NASCIMENTO, A. do. NASCIMENTO, E. L. Enfrentando os termos: o significado de raça, racismo e discriminação racial. Revista para além do racismo: abraçando um futuro interdependente. Estados Unidos, Brasil e África do Sul, jan. de 2000.

${ }^{27}$ POUTIGNAT, P. \& STREIFF-FENART, J. Teorias da etnicidade, seguido de Grupos étnicos e suas fronteiras, de Fredrik Barth. São Paulo, Unesp, 1998.

${ }^{28}$ BRANDÃO, Carlos R. Identidade e etnia. Brasiliense, São Paulo, 1986.

${ }^{29}$ WEBER, M. Relações comunitárias étnicas. In: Economia e sociedade: fundamentos da Sociologia compreensiva. Brasília, UnB, 1994 [1922].
} 


\title{
HÜMANAS
}

\begin{abstract}
Assim como toda comunidade pode atuar como geradora de costumes, atua também de alguma forma, na seleção dos tipos antropológicos, concatenando a cada qualidade herdada probabilidades diversas de vida, sobrevivência e reprodução, tendo, portanto função criadora, e isto, em certas circunstâncias, de modo altamente eficaz.
\end{abstract}

Assim sendo, a atribuição do parentesco realiza a união entre pessoas de descendências raciais diferenciadas, mas que partilham a crença numa origem comum. Hoje, o território é ocupado pelas famílias dos parentes, dos descendentes dos casais fundadores. Todo esse espaço é definido pela descendência e pelas trocas matrimoniais. Nesse sentido, chega-se à conclusão de que, de acordo com uma lógica interna, esse território remanescente de quilombo está dividido em quatro sub-regiões (Olaria, Periquito, Mangueira e Urubu), delimitado-as simbolicamente, pelo parentesco. A interação entre essas sub-regiões se dá através da organização de uma "grande família", o que forma a comunidade dos quilombos. As informações citadas fazem parte dos aspectos gerais da região que é objeto da presente pesquisa: a comunidade remanescente de quilombo da Olaria, localizada no município de Irará.

\section{3 - Aspectos específicos da comunidade pesquisada}

O cotidiano da comunidade da Olaria é marcado por disputas e conflitos, sobretudo a respeito dos recursos naturais, como: árvores, barro para fazer objetos utilitários e água. Essa região possui uma paisagem natural marcada pela presença de uma vegetação que se caracteriza pela existência de árvores espinhosas. Existem as arbóreas-herbáceas (plantas xerófilas), de troncos torcidos, recurvados e de folhas grossas, esparsas em meio a uma vegetação rala e rasteira envolta por campos limpos. Também possuem árvores não muito altas, como: caju da caatinga, barbatimão, o pau-santo, a gabiroba, a sucupira, o pau-terra, a catuaba, dentre outros. Algumas espécies são utilizadas como remédio caseiro: os nativos utilizam raizes, cascas, folhas e sementes dessas árvores como matérias-primas para sua medicina alternativa. 


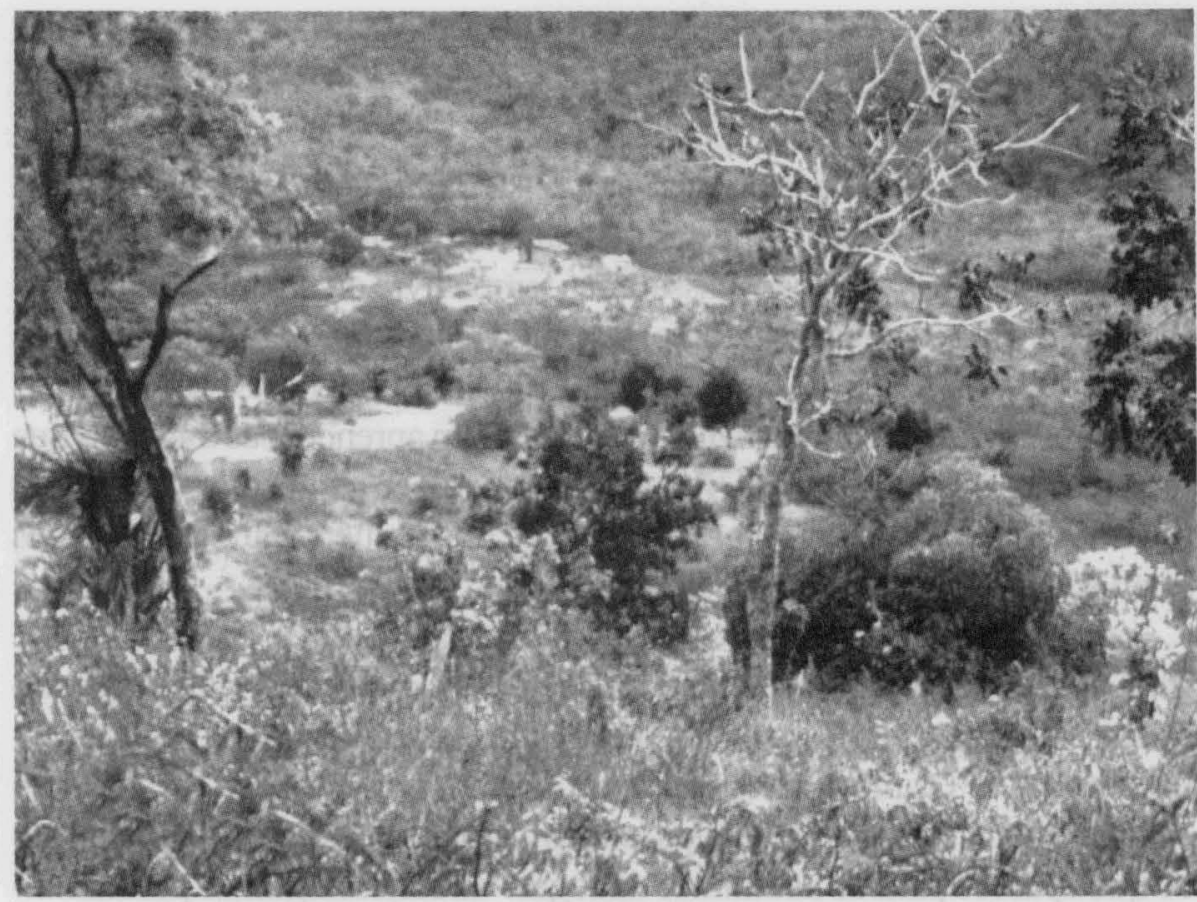

Figura 3

O perfil da vegetação da comunidade da Olaria.

É da mata que se retira a matéria-prima para os banhos de descarrego e remédios caseiros. Os nativos tomam banhos com as folhas da região em rituais, onde utilizam determinados elementos da natureza, de maneira ordenada e com conhecimento de causa, com o intuito de trocar energia entre o indivíduo e a natureza, a fim de fornecer-lhe equilíbrio energético e mental. As pessoas tomam banhos de folhas colhidas na região, com a finalidade de purificarem, limparem e energizarem o corpo e a alma ${ }^{30}$. Para os sujeitos que moram nesse lugar, as folhas têm diversas finalidades e combinações, nomes e considerações: alecrim, gonsalinho, olho-de-boi, folha da guiné, juá, jurubeba, jurema preta, laranjeira do mato, unha do porco, pau d'alho, aroeira, assa peixe, picão, pinhão roxo, pinhão branco, quixabeira, urtiga, vassourinha, carobas, paus d'arco, entre outros. Estas plantas são utilizadas como remédio caseiro e para fazer bebidas: mistura-se cachaça com raízes, folhas,

${ }^{30}$ Segundo D. Anjinha, a farmácia dos nativos é a mata, pois é dela que as pessoas retiram grande parte dos remédios que curam as doenças, como: gripe, dores de barriga, no figado, nos rins, de cabeça, etc. 


\section{HÜMANAS}

cascas, sementes, entre outros, para se criarem diversas receitas de bebidas que servem como remédio. Cada erva ou conjunto de ervas tem sua finalidade em relação a um ou mais tipos de problemas espirituais ou enfermidades.

A paisagem da Olaria produz várias histórias na comunidade. É comum encontrar por ali pessoas dispostas a contarem e ouvirem "causos" por meio de uma atividade lúdica para passarem o tempo livre ou quando estão trabalhando em grupo: amarrando fumo, raspando mandioca, limpando feijão, ou fazendo objetos de cerâmica. Nessas conversas, os indivíduos vão incorporando os valores do grupo em que vivem, e assim aprendem as tradiçōes que regem a organização social. Nessa terra, prevalece a transmissão oral das histórias, dentre as quais aparecem alguns mitos que tratam das relações estabelecidas entre o homem e natureza.

Um dos mais persistentes mitos da Olaria gira em torno da Serra de Irará (região que abriga a comunidade da Olaria e outras comunidades) indica que haveria por ali riquezas em metais, que essa área ocultaria um "carneiro de ouro" "31. Os moradores da Olaria, assim como pessoas que residem em outras localidades do município contam que existe um carneiro gigantesco que aparece para os habitantes da região da serra. Algumas pessoas dizem que ele aparece de dia, e há outras que o vêem à noite, de longe. Os nativos contam que muitos deles já viram esse animal, que sempre aparece com uma estrela resplandecente na testa. Dizem que ele berra junto a uma enorme corrente de ouro, como que indicando que naquele lugar existem grandes riquezas e grandes encantos. O brilho é tão intenso que parece se aviva, com uma luminosidade deslumbrante. A presença dsse carneiro a associada as riquezas enterradas. Segundo, os nativos, essa região já foi alvo de algumas pesquisas arqueológicas que foram motivadas, pelas tradições contadas pelos nativos ${ }^{32}$ :

Inté agora, o povo dizia que aqui na Serra existia ouro. O povo via o carneiro de ouro que pulava de um conto pra outro. Ele brilhava muito, chegava doer os zói das pessoa... Esse carneiro era um siná de ouro.

\footnotetext{
${ }^{31}$ A lenda do carneiro de ouro está presente no imaginário popular dos sujeitos que moram na Serra de Irará e dos outros que residem fora dessa comunidade. Para esse sujeito esse animal mantém relações com os homens, quando aparece para eles a fim de mostrar que existe ouro enterrado na serra.

32 ENTREVISTA: Senhor João de Jesus, negro, nascido em 1912, morador da localidade de Olaria.
} 


\begin{abstract}
Por isso que o povo dizia que aqui tinha ouro... Quando eu era menino argumas pessoas veio aqui olhar que na Serra tinha ouro. Era os doutor engenheiro... A gente não ficou sabendo que ele encontrou ouro, mas depois disso as terras foi cercada....
\end{abstract}

Desse modo, a Serra de Irará (espaço que abriga a comunidade da Olaria), sempre foi vista na região, mais do que uma paisagem. Pois, essa sempre representou uma motivação no imaginário da população, notadamente dos moradores da cidade. A Serra de Irará despertou interesses de pesquisadores, por volta dos anos 40 do século XX. Segundo os nativos, algumas pesquisas foram feitas na região. Os moradores mais velhos garantem que, até hoje, o carneiro de ouro se esconderia no interior da Serra de Irará. Porém, a lenda que mobilizou algumas pessoas, no passado, ainda permanece no imaginário local. Se não existiam minerais preciosos na serra, os nativos não sabem. Embora não tenha sido efetivamente localizado ouro, a notícia serviu de impulso para outras expedições particulares e governistas, que tomaram os caminhos da Serra de Irará, no século XX. Como resultados da busca pelo ouro, temos na região o cercamento definitivo das terras que foram conquistadas pelos ancestrais negros.

Para os moradores da Olaria, outros seres enigmáticos também habitam a região. As pessoas acreditam que, nas matas, moram seres espirituais que exercem relações diretas na comunidade. A caipora é um ser que vive nesses matos. Esse espírito é uma espécie de moleque da floresta, que apronta ciladas para as pessoas que caçam animais e lenha. Essa espiritualidade tanto afugenta as presas, como desorienta o caçador simulando os ruídos dos animais da mata. Essa criatura surpreende especialmente as mulheres que catam lenha no moto. A partir dessa lenda, é comum não região a resistência de catar lenha, nos dias de sexta-feira, que segundo os nativos, é o dia que a caipora mais apronta ${ }^{33}$. A história da caipora demarca que existe uma relação entre seres viventes e espíritos que residem nas florestas ${ }^{34}$.

Mas, dentre os seres visíveis, aparecem nessas matas uma fauna nativa constituída por: tatus, veados, caititus, raposas, gatos do mato, jaracuçu,

${ }^{33}$ ENTREVISTA: Senhor João de Jesus, morador da localidade de Olaria, cedida no dia 14/08/2005.

${ }^{34}$ Essas narrativas desempenham um papel bastante importante na socialização do grupo investigado. 
cobra coral, etc. Esses seres, ao contrário dos mitológicos, deixaram de aparecer para os nativos. Pois, o desflorestamento e caça predatória provocaram o desaparecimento desses animais.

Essa região tem uma população formada por homens, mulheres, crianças e por velhos, tem as suas bases comandadas pelo lado feminino, já que os homens saem do seu convívio familiar para trabalhar em terras distantes do seu local de moradia; na maioria das vezes vão trabalhar em outras propriedades rurais da vizinhança. Nesse caso, a produção agrícola da comunidade vem das terras que não pertencem aos quilombolas, mas é nela que o homem trabalha, recebendo pequenos salários, do valor de sete reis pelo dia trabalhado. Esse trabalho é conhecido na localidade como a tarefa de ganhar dia, uma vez que os homens, em geral, não têm a quem vender o dia, perdem o dia sem trabalhar e, portanto, não ganham nenhum dinheiro. Essa é uma das comunidades rurais mais pobres do município de Irará.

Essa é considerada uma comunidade numerosa, com aproximadamente quinhentas pessoas. Existem 150 casas e 200 famílias, sendo que muitas delas moram sobre o mesmo teto ${ }^{35}$. Existe um riacho que alimenta a comunidade com a sua água, seja para beber ou para o trabalho - o barro que ainda existe, a matéria-prima para a cerâmica, é extraído da sua margem. Isso pode ser um fator que ajuda na invisibilidade da sociedade em relação à comunidade quilombola. Não existem políticas públicas eficientes que contribuam para o bem-estar das comunidades de uma maneira geral. Essas pessoas também são vítimas de um racismo velado na sociedade local, fruto de todo um processo histórico.

Dentro da comunidade não existe um posto de saúde. Existe apenas uma escola (Escola Municipal Ana Souza) e uma casa de farinha comunitária. Ambas têm grande serventia a todos os moradores, pois é nesse espaço que as pessoas fazem reuniões, da associação dos moradores. A população é predominante católica, e o padroeiro da localidade é São Cosme e São Damião. Existe uma igreja bastante simples onde ocorrem os cultos religiosos e reuniões. Segundo, os moradores, essa igreja foi construída em 1998, e os moradores escolheram o santo protetor do local, através de uma votação. Grande parte dos moradores dessa região já era devota de São Cosme e por isso este foi escolhido, uma vez que nas residências já era muito cultuado.

${ }^{35}$ SECRETARIA MUNICIPAL DE SAÚDE DE IRARÁ. Programa de controle de epidemias, 2006. 


\begin{abstract}
Além de fazer rezas para São Cosme, as pessoas dessa comunidade também são devotas de outros santos. Todas as casas têm muitos quadros de santos nas paredes. Têm muitas festas religiosas. As pessoas têm o hábito de "se benzer" antes de sair de casa. A comunidade tem um amor muito grande pelas raízes culturais dos seus antepassados.

As atividades econômicas praticadas na comunidade são a agricultura e criação de animais, sendo estas destinadas a subsistência das famílias. A grande maioria destas atividades é realizada em terrenos individuais, situados nas proximidades das residências. Os principais produtos cultivados são: milho, feijão e mandioca.

Hoje em dia, os atuais moradores dessa região não possuem títulos de terra. $\mathrm{O}$ acesso a terra satisfaz aos princípios do parentesco, ou seja, ocorre através da descendência, filiação, ou da aliança matrimonial. Assim, aparece um sistema de terras de herança, comungado com terras de parentes. A comunidade é formada por esse território que é parcelado por pequenas propriedades, onde existem uma casa e poucos metros de terras, que são utilizados para plantar parcos produtos agrícolas e criar animais. Essa questão é conseqüência da especulação imobiliária, a ambição dos fazendeiros circunvizinhos, que com a falta de documentação legal por parte de seus legítimos donos foram ocupando a região e instalando propriedades privadas e bloqueadas do uso coletivo ${ }^{36}$. Nesse caso, o problema mais grave de todos, nessa região, é que a terra que não perspectiva de ser identificado de forma coletiva para se ter o reconhecimento legal.
\end{abstract}

\title{
4 - Considerações finais
}

Presentemente, os moradores da comunidade de Quilombo da Olaria estão vivendo um processo de construção identitária: elas têm consciência que de descendem diretamente de ex-escravos africanos, e sua característica comum está ligada ao "desenvolvimento de práticas de resistência na manutenção e reprodução de seus modos de vida". Conforme voz corrente na comunidade, as terras que são habitadas pelos nativos foram doadas pelos ancestrais. Essa história tem iníco no momento em que colonizadores e colonizados firmaram as bases iniciais dos seus relacionamentos na sociedade local.

\footnotetext{
36 Idem.
} 
Em decorrência disso, a comunidade da Olaria acabou por ocupar no sistema finalmente estabelecido, em se tratando da sua situação física, geográfica e cultural, um lugar muito além das formas pelas quais a comunidade é integrada ao entorno regional. Dessa forma, os nativos almejam relacionar a memória da escravidão e da resistência com a atual discussão sobre o conceito de quilombos. Através dessas atividades, as pessoas que ali residem, planejam executar um trabalho respaldado na memória dos mais velhos, em que últimos passarão a fazer um retorno àquele passado fincado na escravidão e a lembranças pouco ou nada prazerosas que costumam se apagar da memória.

O alvo inicial desse povo é a conquista da titulação das terras das comunidades e a construção de um perfil de identidade quilombola que se firme politicamente, posto que a legislação brasileira já adota este conceito de comunidade quilombola e reconhece que a determinação da condição quilombola advém da auto-identificação. O auto-reconhecimento garantido no Decreto $\mathrm{n}^{\circ} 3.572$, de 22 de julho de 1999 só foi estabelecido na legislação ederal em novembro de 2003, através do Decreto $n^{\circ} 4.887$. Depois da proximação dos sujeitos, através dos encontros promovidos na associação ocal, notou-se o quanto essas pessoas estão ávidas por entenderem o significado da palavra quilombos, a fim de mudarem a sua comunidade. De acordo com o seguinte depoimento percebe-se ${ }^{37}$ :

A gente quer saber por que agora tá dizendo que aqui é um quilombo. Antes o povo mais velho falava da escravidão e dessa história que os negros se escondiam no mato. Mas, agora a gente quer saber por que as pessoas se interessaram para dizer que aqui é um quilombo. Eu ouvi na televisão que o quilombola tem direito a vaga na universidade. Eu quero saber como a gente pode ter vaga para estudar na universidade, porque ainda eu sonho em continuar com meus estudos. Além disso, tem outras coisas que sempre aparece na televisão, mas a gente não entende bem o que passa na televisão. A gente quer saber como nós é visto como quilombola e que a gente pode ganhar com isso...

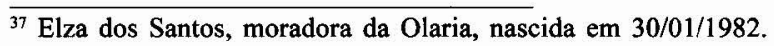


Etnicidade e memória entre quilombolas em Irará, Bahia Jucélia Bispo dos Santos

Foi possível perceber que esses sujeitos já não querem mais assumir uma postura passiva diante da sua trajetória coletiva. As pessoas que moram nessas comunidades sonham com a transformação do lugar. Dentre as principais questões que as pessoas almejam, aparecem as seguintes: melhoria e/ ou implantação dos serviços de saúde com qualidade nas comunidades; implantação do Programa Saúde da Família nas comunidades; implementação de ações efetivas de detecção e controle da anemia falciforme nas comunidades; atendimento odontológico; cursos que promovam o desenvolvimento das potencialidades dos jovens das comunidades nas áreas de educação e de qualificação profissional; realização de cursos de alfabetização para jovens e adultos; melhor estruturação da escola existente na comunidade com suporte de materiais pedagógicos; reforma e ampliação da escola que existe na região (Escola Municipal Ana Souza Carneiro); transporte escolar com qualidade e segurança para os jovens que estudam fora da comunidade; revitalização do trabalho com a cerâmica; e demarcação das terras que pertenceram aos ancestrais.

Hoje, os sujeitos que moram na comunidade quilombola da Olaria querem recuperar da história desses grupos, a fim de fomentarem a luta por terras. Portanto, tornou-se interessante a aproximação dos sujeitos pesquisados para, juntos pensarem no contexto das desigualdades e exploração coletiva. Uma vez que nesses espaços os indivíduos já nascem com papéis definidos- uns nascem para mandar e outros para obedecer, uns oprimem e outros são oprimidos- a prática da pesquisa pode ser um meio de promover a transformação social em busca da igualdade e da valorização do ser humano.

\section{Referências bibliográficas}

ANJOS, R. S. A. Projeto mapeamento dos remanescentes de quilombos no Brasil-sistematização dos dados e mapeamento- Relatório Técnico, Fundação Palmares, Brasília, 1997.

ARAGÃO, A. Pelourinhos da Madeira, Funchal, 1959, Luís Chaves, Os Pelourinhos de Portugal, Gaia, 1930.

BRANDÃO, C. R. Identidade e etnia. Brasiliense, São Paulo, 1986.

FUNDAÇÃO CULTURAL PALMARES (FCP), do Ministério da Cultura. Projeto de melhoria da identificação e regularização de terras das comunidades quilombolas brasileiras, 2003. 


\section{HÜMANAS}

GOFFMAN, E. (1988). Estigma: notas sobre a manipulação da identidade deteriorada. (M. B. M. L. Nunes, Trad.). Rio de Janeiro: Zahar Editores. (Original publicado em 1963).

IBGE. Enciclopédia dos municipios brasileiros. Rio de Janeiro: IBGE, 1957.

NASCIMENTO, A. e LARKIN, E. Enfrentando os termos: o significado de raça, racismo e discriminação racial. In: Revista para além do racismo: abraçando um futuro interdependente. Estados Unidos, Brasil e África do Sul, jan. de 2000.

NOGUEIRA, A. Histórico do município de Irará. Prefeitura Municipal de Irará, 1988.

NEVES, E. F. Da sesmaria ao minifúndio (um estudo de história regional e local). Salvador: Editora da Universidade Federal da Bahia; Feira de Santana: Universidade Estadual de Feira de Santana, 1998.

POUTIGNAT, P. e STREIFF-FENART, J. Teorias da etnicidade, seguido de grupos étnicos e suas fronteiras de Fredrik Barth. São Paulo: Unesp, 1998.

SECRETARIA MUNICIPAL DE SAÚDE DE IRARÁ. Programa de controle de epidemias, 2006

WEBER, M. Relações comunitárias étnicas. In: Economia e sociedade: fundamentos da sociologia compreensiva. Brasília: UnB, 1994 [1922]. 